\title{
MODERNISMO: ÉTICA X ESTÉTICA
}

\author{
Maria Tereza Carneiro Lemos*
}

RESUMO: A partir da avaliação do movimento modernista feita por Mario de Andrade e Oswald de Andrade nas conferências "Movimento modernista" e "O caminho percorrido", na década de 40, busco uma compreensão da questão ética que, segundo os autores, estava ausente na proposta modernista tornando o movimento "gravemente precário". O desinteresse pelos problemas sociais e políticos de sua geração gerou um "conformismo legítimo”, nas palavras de Mario de Andrade, e acabou por criar, nos seus discursos, um confronto entre o valor estético e ético na arte.

PALAVRAS-CHAVE: Modernismo, Ética, Estética.

ABSTRACT: From the analysis of modernism made by Mario de Andrade and Oswald de Andrade on the lectures "Movimento modernista" and "O caminho percorrido", given in the 40's, I look for an understanding of the ethical question which, according to the authors, was missing in the modernist proposal, turning the movement into a "seriously precarious" one. According to Mario de Andrade, the lack of attention given to social and political problems of his generation created, in his own words, a "legitimate resignation" and ended up provoking, in his speeches, a confrontation between the aesthetical and ethical values in the Arts.

KEY WORDS: Modernism, Ethics, Esthetics.

*Doutoranda em Literatura Brasileira - PUC-RJ 
A década de 40 foi bastante significativa na avaliação do movimento modernista, principalmente no que se refere ao testemunho deixado pelos dois grandes expoentes do movimento: Mário de Andrade, na conferência o "Movimento modernista" proferida no Itamarati, em 1942, e Oswald de Andrade, na conferência "O caminho percorrido" proferida em Belo Horizonte, em 1944. Ambos, distantes 20 anos da revolução da qual foram os grandes protagonistas, sentiram-se impelidos a deixar para a posteridade os seus testamentos intelectuais. As conferências acabaram se tornando, também, uma reavaliação confessional dos dois autores, considerando-se que cada um abordava de forma bem diversa e pessoal seu caminho percorrido.

Gostaríamos de expor aqui, não exatamente uma análise comparativa entre as duas conferências, nem tampouco nos ater a uma análise pessoal, mas ressaltar um ponto convergente que curiosamente surge no discurso dos dois autores: a questão ética.

Oswald de Andrade, depois de ter gradualmente perdido espaço junto à intelectualidade brasileira, usou parte do seu discurso para defender-se do ostracismo e de alguns desentendimentos que surgiram com o tempo, acabando por imprimir à sua fala egocentrismo e ressentimento, valorizando seus feitos e sua mágoa.

Se alguma coisa eu trouxe das minhas viagens à Europa dentre duas guerras, foi o Brasil mesmo. O primitivismo nativo era o nosso único achado de 22 (...). A Antropofagia foi na primeira década do modernismo, o ápice ideológico, o primeiro contato com nossa realidade política porque dividiu e orientou no sentido do futuro. ${ }^{1}$

O discurso é marcado pela semântica da guerra e do combate, em que o autor ataca, com seu conhecido deboche, os seus inimigos que surgem contra os seus "aliados".

Quem havia de publicar essa carta senão a ratazana 
em molho-pardo que é o Sr. Cassiano Ricardo? Nesse documento vem à tona o estado de sítio que proclamaram contra mim os amigos da véspera modernista de 22. Pretendia-se que eu fosse esmagado pelo silêncio, talvez por ter lançado Mário de Andrade e prefaciado o primeiro livro de Antônio de Alcântara Machado. (...) Tudo isso teria um vago interesse anedótico se não viesse elucidar as atitudes políticas em que se bipartiu o grupo oriundo da Semana. Comigo ficaram Raul Bopp, Oswaldo Costa, Jaime Adour da Câmara, Geraldo Ferraz e Clóvis Gusmão. ${ }^{2}$

Este espírito de guerra, muito ao gosto futurista, reflete o próprio espírito destruidor que dominou o modernismo paulista em que Oswald parecia ainda estar imerso. Atitude que destoa essencialmente da de Mário de Andrade que, numa confissão marcada pela humildade e coragem, minimizava seus atos e o próprio movimento do qual tornou-se o grande ícone, apresentando as contradições do afã destruidor modernista: "o movimento modernista foi essencialmente destruidor. Até destruidor de nós mesmos” (p. 240). Livre de autodefesas e ressentimentos, Mário de Andrade reavalia o movimento, expondo questões que possibilitam uma nova leitura do modernismo paulista.

Numa longa análise do passado com os olhos do presente, Mário confessa que, na verdade, eles, modernistas de 22, tinham "apenas servido de altifalantes de uma força universal e nacional muito mais complexa que [eles]”. E não deixa de mostrar um descompasso entre as atitudes do seu grupo e a realidade brasileira, desmistificando os heróis do movimento:

Todo esse tempo destruidor do movimento modernista foi pra nós tempo de festa, de cultivo imoderado do prazer. E se tamanha festança diminuiu por certo nossa capacidade de produção e serenidade criadora, ninguém pode imaginar como nos divertimos. ${ }^{3}$ 
No entanto, reconhece a indiscutível importância do movimento que, mesmo com todo o cultivo imoderado do prazer, e distante da "dor" real do país, não foi o fator das mudanças políticas e sociais posteriores a ele, mas acabou sendo um "preparador" dessas mudanças, e um "criador de um estado de espírito revolucionário e de um sentimento de arrebatação". E defende o papel da sua geração como preparadora do espírito de liberdade que dominou a geração de 30.

Resume em três princípios básicos, a nova realidade que o modernismo criou: o direito permanente à pesquisa estética; a atualização da inteligência artística brasileira; e a estabilização de uma consciência artística nacional. O primeiro princípio representa a liberdade de experimentação conquistada pelos artistas brasileiros que, à exceção dos românticos, "jogaram sempre colonialmente no certo. Repetindo e afeiçoando estéticas já consagradas, [eliminando] assim o direito de pesquisa, e conseqüentemente de atualidade." (p. 243).

O espírito destruidor veio da Europa ("é muito mais exato imaginar que o estado de guerra da Europa tivesse preparado em nós um espírito de guerra, eminentemente destruidor” p. 235) como veio da Europa "o espírito modernista e as suas modas" (p. 236), mas Mário defende-se: chamá-los de "antinacionalistas" ou "antitradicionalistas europeizados" era "falta de sutileza crítica". E defende São Paulo com exemplos da tradição regionalista do estado, como a arquitetura e o urbanismo neocolonial nascidos também lá, até concluir "Desta ética estávamos impregnados"(p. 235). A ética nacionalista.

Paralelamente ao afã destruidor que dominava esses artistas, o nacionalismo representou a grande construção modernista, e está aí a atitude ética: a construção de símbolos, imagens e instrumentos que representam valores (nacionais) e rejeitam antivalores (estrangeiros). Nas palavras de Alfredo Bosi:

A translação do sentido da esfera ética para a estética é possível, e já deu resultados notáveis, quando o narrador se põe a explorar uma força catalisadora da vida em 
sociedade: os seus valores. À força desse ímã não podem subtrair-se os escritores enquanto fazem parte do tecido vivo de qualquer cultura. ${ }^{4}$

A estética nacionalista junto à pesquisa da "língua brasileira", que confrontava os fortes valores nacionais aos fracos antivalores estrangeiros, eliminava o academismo reinante tanto no tema quanto na linguagem das artes naturalistas dominantes, e ao mesmo tempo procurava construir uma outra realidade através das artes. No entanto, Mário não vê no nacionalismo modernista, a "verdadeira consciência da terra". Este espírito atualizado que se radicava na terra brasileira, "não se deu sem alguma patriotice e muita falsificação ...” gerando um "conformismo legítimo", e observa:

o que caracteriza essa radicação na terra, num grupo numeroso de gente modernista, de uma assustadora adaptabilidade política, palradores de definições nacionais, sociólogos otimistas, o que os caracteriza é um conformismo legítimo, disfarçado e mal disfarçado nos melhores, mas na verdade cheio de uma cínica satisfação. A radicação na terra, gritada em doutrinas e manifestos, não passava de um conformismo acomodatício. ${ }^{5}$

Completa que "a verdadeira consciência da terra levava fatalmente ao não- conformismo e ao protesto" (p. 244). O modernismo paulista no seu afã nacionalista e festivo, acabou se desviando desta "verdadeira consciência", quando representou o Brasil de forma simbólica e otimista. Desmistifica também a construção da "língua brasileira" que, por falta de critérios científicos adequados, acabou reduzida a manifestações individuais, aderindo-se também a um certo espírito festivo. Mário conclui: "era ainda o mesmo caso dos românticos: não se tratava duma superação da lei portuga, mas duma ignorância dela.”6

Inserido agora no contexto mundialmente conturbado da $2^{\circ}$ guerra, em que o engajamento tornava-se uma questão ética, 
Mário acabava muitas vezes reduzindo o seu movimento a um conformismo infantil. Na verdade, a rígida autocobrança que faz é em relação ao engajamento social e político, ou o interesse pelo humano, que o seu movimento não teve. A estética se faz através da arte que é uma expressão do social:

Mas a inteligência estética se manifesta por intermédio de uma expressão interessada da sociedade, que é a arte. Esta é que tem uma função humana, imediatista e maior que a criação hedonística da beleza. E dentro dessa funcionalidade humana da arte é que o assunto adquire um valor primordial e representa uma mensagem imprescindível. Ora, como atualização da inteligência artística é que o movimento modernista representou papel contraditório e muitas vezes gravemente precário. 7

O segundo princípio, da "atualização da inteligência artística brasileira”, por apresentar contradições profundas em relação às necessidades sociais e políticas, parece ser, segundo Mário, a grande falha do movimento. Diferente da "liberdade de pesquisa estética" que lida com a forma, a técnica e a beleza na arte, a "atualização da inteligência" lida com a dimensão mais ampla da arte, ou seja, com a "força interessa da vida". E conclui a sua conferência:

Si tudo mudávamos em nós, uma coisa nos esquecemos de mudar: a atitude interessada diante da vida contemporânea. (...) uma coisa não ajudamos verdadeiramente, duma coisa não participamos: o amilhoramento político-social do homem. E esta é a essência mesma da nossa idade" ${ }^{8}$

E cobra da arte sua missão ética:

Sei que é impossível ao homem, nem ele deve abandonar os valores eternos, amor, amizade, Deus, a natureza. Quero exatamente dizer que numa idade humana como a que vivemos, cuidar desses valores apenas e se refugiar 
neles em livros de ficção e mesmo de técnica, é um abstencionismo desonesto e desonroso como qualquer outro (...) De resto, a forma política da sociedade é um valor eterno também. ${ }^{9}$

E aponta o movimento de 30 como aquele que deixa de lado o caráter destruidor e assume uma construção de "uma fase mais calma, mais modesta e quotidiana, mais proletária” (p. 242). Agora, em 1942, o caráter construtivo da arte tornava-se uma questão premente. $\mathrm{O}$ espírito destruidor das vanguardas parecia já se desgastar e a arte deveria, mais do que nunca, realizar sua função social e política.

O embate, ao final da conferência, ganha um caráter de conclamação revolucionária: "Façam ou se recusem a fazer arte, ciências, ofícios. Mas não fiquem apenas nisto, espiões da vida, camuflados em técnicos de vida, espiando a multidão passar. Marchem com as multidões."(p. 255). O que se assemelha às palavras de Oswald de Andrade, em Belo Horizonte, que de maneira ardentemente revolucionária, conclama os intelectuais como os guerreiros da sociedade:

Com a guerra, chegamos aos dias presentes. E os intelectuais respondem a um inquérito. Se a sua missão é participar dos acontecimentos. Como não? Que será de nós, que somos as vozes da sociedade em transformação, portanto os seus juízes e guias, se deixarmos que outras forças influam e embaracem a marcha humana que começa? O inimigo está vivo e ainda age (...) O papel do intelectual e do artista é tão importante hoje como o do guerreiro de primeira linha." ${ }^{10}$

Da mesma forma, conclama os mineiros a se unirem a seus irmãos paulistas no combate heróico em prol da utopia e estende o seu chamado a todos os irmãos brasileiros:

Tomai lugar em vossos tanques, em vossos aviões, intelectuais de Minas! Trocai a serenata pela 
metralhadora! Parti em espírito com os soldados que vão deixar suas vidas na carnificina que se trava por um mundo melhor. (...) Vinde com vossos irmãos de São Paulo, com vossos, com vossos irmãos do Norte e do Sul, fazer com que se cumpram os destinos do Brasil! ${ }^{11}$

Os dois discursos terminam conclamando os homens (intelectuais) à revolução. Enquanto Mário, em 1942, julgava o passado de forma às vezes cruel, cobrando uma atitude que não foi possível realizar 20 anos antes, Oswald, imbuído da ideologia marxista, apontava para um futuro revolucionário.

A primeira literatura modernista, sendo uma literatura de resistência aos valores artísticos vigentes era implicitamente resistente aos valores ideológicos que determinavam esta arte. Mas este fenômeno de resistência se fazia como um processo inerente à escrita e não como tema dessa escrita. É compreensível que Mário, em 1942, quando analisava o primeiro modernismo, tivesse percebido que, depois da literatura de 30 a sua geração tornava-se anacrônica política e socialmente. Os valores que nortearam a arte desta primeira geração estavam sem dúvida mais ligados ao fenômeno estético do que ao fenômeno ético da resistência.

\section{NOTAS BIBLIOGRÁFICAS}

${ }^{1}$ ANDRADE, Mario de. O movimento modernista. In.: Aspectos da literatura brasileira. São Paulo: Martins, p. 96, s/d.

${ }^{2}$ ANDRADE, Oswald de. O caminho percorrido. In.: Ponta de lança. Rio de Janeiro: Civilização Brasileira, p. 96, 1972.

${ }^{3}$ ANDRADE, Mario de. O movimento modernista. In.: Aspectos da literatura brasileira. São Paulo: Martins, p. 241 s/d.

${ }^{4}$ BOSI, Alfredo. Literatura e resistência. São Paulo: Companhia 
das Letras, p. 120, 2002.

${ }^{5}$ ANDRADE, Mario de. O movimento modernista. In.: Aspectos da literatura brasileira. São Paulo: Martins, p. 243, s/d.

${ }^{6} I d e m$, p. 245.

${ }^{7} I d e m$, p. 252.

${ }^{8}$ Idem, p. 252.

${ }^{9}$ Idem, pp. 252, 255. 
129 